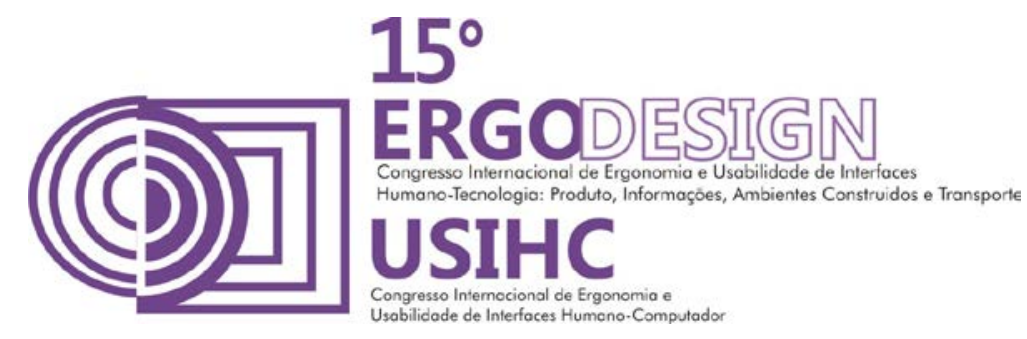

\title{
AVALIAÇÃO ERGONÔMICA DA EXTRAÇÃO MANUAL DE RAÍZES DE MANDIOCA EM PROPRIEDADES AGRÍCOLAS FAMILIARES A PARTIR DO RASTREAMENTO DE MOVIMENTOS 3D (X-SENS)
}

\section{ERGONOMIC EVALUATION OF MANUAL CASSAVA EXTRACTION IN FAMILY FARMS USING 3D MOTION TRACKING (XSENS)}

\author{
CUNHA, Julia Marina (1) \\ MERINO, Giselle Schmidt Alves Diaz (2) \\ MERINO, Eugenio Andrés Díaz (3) \\ (1) Universidade Federal de Santa Catarina, Graduanda. \\ e-mail:juliamarinac@gmail.com \\ (2) Universidade Federal de Santa Catarina / Universidade Estadual de Santa Catarina, \\ Doutora. \\ e-mail:gisellemerino@gmail.com \\ (3) Universidade Federal de Santa Catarina, Doutor. \\ e-mail:eugenio.merino@ufsc.br
}

\begin{abstract}
RESUMO
O trabalho agrícola em propriedades familiares caracteriza-se pelo elevado esforço físico, considerando a limitada mecanização do setor. Esta situação acarreta reflexos na saúde dos agricultores, comprometendo sua produtividade. Esta pesquisa visa identificar os fatores de risco nas atividades de cultivo da mandioca e a definição de diretrizes para desenvolvimento de ferramenta manual. A avaliação da situação real, associada ao rastreamento de movimentos em 3D baseados na tecnologia MEMS de sensores inerciais em miniatura (Xsens), permitiu identificar os pontos críticos da perspectiva biomecânica, e definir as diretrizes para o projeto de uma ferramenta manual para arranque de raízes de mandioca.

Palavras-chave: agricultura familiar; mandioca; ferramenta manual; saúde; design; ergonomia; Xsens

\section{ABSTRACT}

The agricultural labor on family farms is characterized by high physical effort, considering the limited sector mechanization. This situation reflects on the health of farmers, affecting their productivity. This research aims to identify risk factors in cassava farming activities and the definition of guidelines for manual tool development. The evaluation of the actual situation, associated with tracking movements in $3 D$ based on MEMS miniature inertial sensor technology (Xsens), allowed to identify the critical points from a biomechanical perspective, and set the guidelines for the design of a hand tool for extract cassava roots.
\end{abstract}




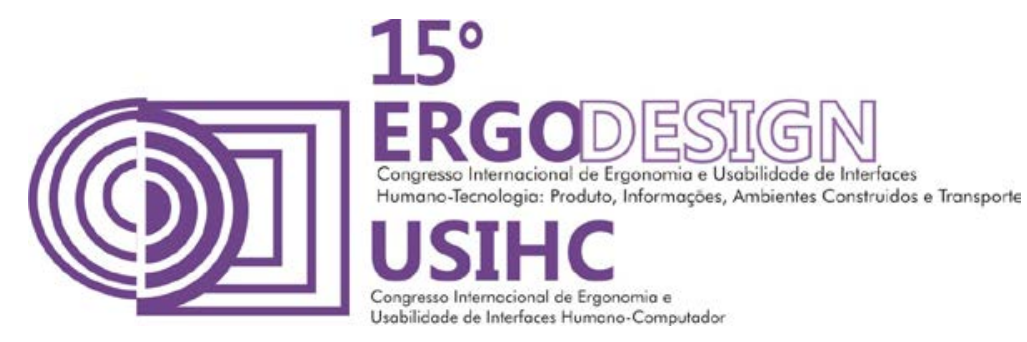

\section{INTRODUÇÃO}

A agricultura é um dos principais setores da economia brasileira, o Brasil se destaca no cenário mundial de produção agrícola. Define-se por agricultura, a lavoura ou o cultivo da terra e inclui todos os trabalhos relacionados com o tratamento do solo e a plantação de vegetais. $O$ agronegócio vem sendo valorizado como método de combate à fome, destacando-se neste aspecto a agricultura familiar. Sendo agricultura familiar, uma forma de produção onde predomina a interação entre gestão e trabalho; são os agricultores familiares que dirigem 0 processo produtivo, dando ênfase na diversificação e utilizando o trabalho familiar, eventualmente complementado pelo trabalho assalariado (MDS, 2009).

A nível mundial, $70 \%$ dos alimentos são produzidos por agricultores familiares, e $40 \%$ das famílias do mundo dependem da agricultura familiar como forma de vida (RURAL FORUM, 2013). A agricultura familiar detém cerca de $30 \%$ da produção agrária no mundo, no Brasil responde por $10 \%$ do PIB e em Santa Catarina é responsável por mais de $50 \%$ dos produtos da cesta básica (IBGE, 2006). Dois terços dos postos de trabalho estão no campo e Santa Catarina ganha destaque no cenário nacional com $90 \%$ da produção rural, correspondendo a 180 mil famílias, que são responsáveis por 4 alimentos de cada 10 que chegam à mesa. Entre os cultivos que se destacam, a mandioca (Manihot esculenta Crantz) constitui um dos principais alimentos energéticos para mais de 700 milhões de pessoas, principalmente nos países em desenvolvimento (EMBRAPA). O cultivo da mandioca por agricultores familiares envolve diversas tarefas desde o plantio até a colheita da raiz, em sua maioria as tarefas são executadas manualmente devido à inexistência de ferramentas auxiliares e a impossibilidade econômica de mecanização. A mandioca tem considerável importância econômica e social para Santa Catarina, uma vez que são 27.605 estabelecimentos familiares envolvidos com a prática (FRANÇA; GROSSI; MARQUES, 2009)

A agricultura familiar e a ergonomia - disciplina científica que trata da compreensão das interações entre os seres humanos e outros elementos de um sistema (IEA, 2000) - relacionamse de modo a melhorar as condições de trabalho do agricultor, sendo a ergonomia responsável pela identificação dos fatores de riscos e oportunidades de melhoria de todos os elementos envolvidos na tarefa.

Destaca-se o limitado acesso da agricultura familiar à pesquisas e projetos que venham auxiliar na saúde e produtividade do setor como principal motivação para a pesquisa. Em estudos no setor agrícola na Califórnia, revela-se que quase 43\% dos agravos à saúde referidos pelos trabalhadores são distensões e entorses, localizadas, geralmente, na coluna lombar e ocasionadas em $25 \%$ dos casos, por sobrecarga física no trabalho (AGSAFE, 2001). Estes dados sugerem uma alta incidência de problemas múscul-esqueléticos, mais especificamente os Distúrbios Músculo-esqueléticos Relacionados ao Trabalho (DORT), nos quais é evidente 0 estresse biomecânico de repetição causado pelos fatores de risco ergonômicos, uma vez que 0 trabalho na agricultura envolve todos os fatores associados a esses distúrbios.

A principal contribuição desta pesquisa está na aplicação prática do conhecimento científico junto ao setor da agricultura familiar, especificamente o cultivo de mandioca, tendo verificado-se como problema central o reflexo negativo na saúde e produtividade dos agricultores familiares que não dispõem de ferramentas adequadas a realização das suas atividades. 


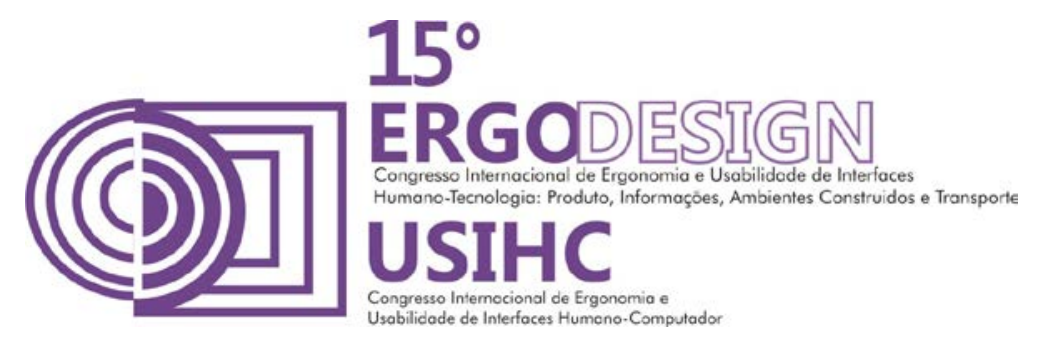

Segundo levantamento realizado, outras pesquisas vem diagnosticando os problemas de saúde e identificando oportunidades de melhoria, com o desenvolvimento de ferramentas: Egli et al (1943), já haviam realizado estudos ergonômicos quando ao gasto de energia no trabalho com a enxada comparando os tipos de solo e o tipo de enxada. O serrote foi objeto de estudos para diversos autores, Lehmann (1962) observou o despendimento de energia ao serrar a madeira e as variáveis da tarefa (KROEMER;GRANDJEAN, 2005).

Entretanto, para os casos propostos nesta pesquisa, os exemplos são limitados. Identificar os fatores de risco nas atividades de cultivo da mandioca e definir diretrizes para desenvolvimento de ferramenta ergonômica auxiliar, a partir de estudo postural das atividades e o objetivo desta pesquisa. As soluções propostas, que consideram os aspectos ergonômicos, poderiam reduzir significativamente os problemas de saúde e consequentemente impactar positivamente a produtividade, trazendo ganhos às famílias.

\section{METODOLOGIA}

Dividem-se os procedimentos em duas fases principais, revisão da literatura e ergonomia aplicada. Quando da revisão da literatura, classifica-se a pesquisa aplicada, sendo esta um conjunto de ações, propostas para encontrar a solução para um problema, com o objetivo de gerar conhecimentos para aplicação prática (SILVA, 2005).

De acordo com os objetivos a pesquisa pode ser caracterizada como exploratória, envolvendo levantamento bibliográfico quanto ao problema em questão. Com base nos procedimentos técnicos, caracteriza-se como pesquisa bibliográfica, desenvolvida quase que exclusivamente com base em fontes bibliográficas, grande parte dos estudos exploratórios podem ser classificados como tal (GIL, 2002).

Foram realizadas pesquisas nas bases de dados Science Direct, PubMed, LILACS, Google Acadêmico e Biblioteca Digital de Teses e Dissertações utilizando as seguintes palavras chave e as correspondentes em inglês: agricultura familiar, lesões ocupacionais, lesões músculoesqueléticas, cultivo de mandioca, ergonomia no trabalho, ergonomia na agricultura.

Quanto aos métodos, para obtenção das informações específicas com relação à extração manual de mandioca, utilizaram-se as técnicas de observação sistemática - quando há planejamento ou preparação (MARKONI; LAKATOS, 2003) - que neste caso dispõe de instrumentos de coleta. Para possibilitar a avaliação dos riscos músculoesqueléticos, utiliza-se 0 equipamento de captura de movimentos X-Sens MVN Biomech. Este, possui sensores que são colocados no usuário, a partir de algoritmos de fusão dos sensores gera-se um modelo biomecânico que concentra os dados coletados e permite posterior análise dos movimentos. Esses procedimentos foram conjugados com análise de fotos e vídeos.

\section{REVISÃO DA LITERATURA}

Guérin et al. (2001), atribuem diretamente a atividade profissional ao estado de saúde de um trabalhador, as relações da saúde com o trabalho não são necessariamente acidentes ou doenças originárias das atividades trabalhistas, podendo também influenciar positivamente à saúde do trabalhador. 


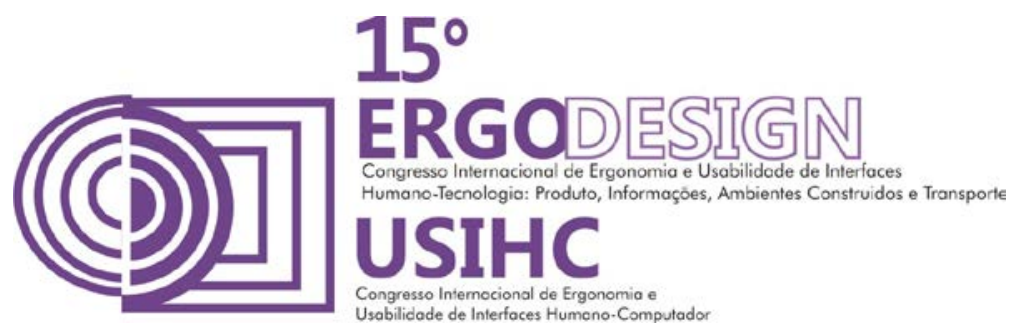

O trabalho agrícola, juntamente com a mineração e construção civil, classificam-se como trabalhos árduos, devido a pouca mecanização das tarefas e os equipamentos e ferramentas rudimentares ainda utilizados. A aplicação de conhecimentos ergonômicos poderia aperfeiçoar os métodos destes setores (IIDA, 2005).

Ainda, segundo Kroemer e Grandjean (2005), pode-se caracterizar como trabalho pesado qualquer atividade que exige grande esforço físico, este evidencia-se pela exigência extrema de coração e pulmões. O trabalho pesado é comum na agricultura, entre outras áreas, e sua severidade pode ser avaliada utilizando o consumo de energia e esforço cardíaco impostos pela tarefa.

Segundo estudos da AgSafe (2001) no setor agrícola da Califórnia, todos os anos mais de 20.000 trabalhadores agrícolas sofrem lesões incapacitantes, essas lesões resultam em diminuição da produtividade, custos com despesas médicas além do sofrimento dos trabalhadores. A ergonomia aplicada neste setor, possui potencial para reduzir os agravos à saúde dos trabalhadores rurais, resultando em mudanças significativas na qualidade de vida destes trabalhadores e como consequência, aumentando a produtividade (JAFRY; O'NEILL, 2000). Os riscos músculoesqueléticos aos que são expostos os trabalhadores agrícolas estão extremos se comparados aos demais setores, são estas as lesões não fatais mais comuns entre aqueles envolvidos em práticas de trabalho intensivo (FATHALLAH, 2010). Segundo o United States Departament of Labor (1999), destacam-se entre os problemas de saúde dos trabalhadores agrícolas, dores na região escapular, ombros, braços e mãos.

Ressaltando a importância dessa análise para a saúde do trabalhador agrícola, uma vez que o dado mais recente da Previdência Social (2012) indica que houveram 705,2 mil acidentes de trabalho no Brasil em 2012, destes, 4\% ocorreram no setor agropecuário. Dados relacionados diretamente a não aplicação ou má aplicação da ergonomia nas ferramentas manuais e condição de trabalho do agricultor.

A mecanização na agricultura vem se estabelecendo em países em desenvolvimento e apesar dos avanços da tecnologia, na agricultura familiar ainda predominam as atividades realizadas manualmente principalmente devido à questões econômicas. Constantemente o trabalhador adota posturas inadequadas prejudiciais à saúde ao realizar tarefas na lavoura. A dor nas costas é a queixa mais comum da população no Brasil (FLEMING, 2003).

Com base nos critérios de classificação do Programa Nacional da Agricultura Familiar (Pronaf), estima-se que a agricultura familiar em Santa Catarina representa um universo de 180 mil famílias, ou seja, mais de $90 \%$ da população rural (MDA, 2014). Estas famílias de agricultores, apesar de ocuparem apenas $41 \%$ da área dos estabelecimentos agrícolas, são responsáveis por mais de $70 \%$ do valor da produção agrícola e pesqueira do estado (DINIZ; SCHARMACH, 2011). Quanto a participação da agricultura familiar em algumas culturas selecionadas, destacase a produção de mandioca, que representa $87 \%$ do total nacional.

A mandioca, também conhecida como macaxeira ou aipim, é originária do Brasil, possivelmente do sudoeste da amazônia (HILLOCKS; THRESH; BELLOTTI, 2001). É um dos alimentos de maior consumo no Brasil, considerando o período de 1993 à 2013, o Brasil é o segundo maior produtor de mandioca do mundo, produzindo em média 23 milhões de toneladas por ano (FAO, 2014). A raiz tem importância mundial, desempenha um papel vital para a segurança alimentar na economia rural dos países da África subsaariana (DZIEDZOAVE et al) 


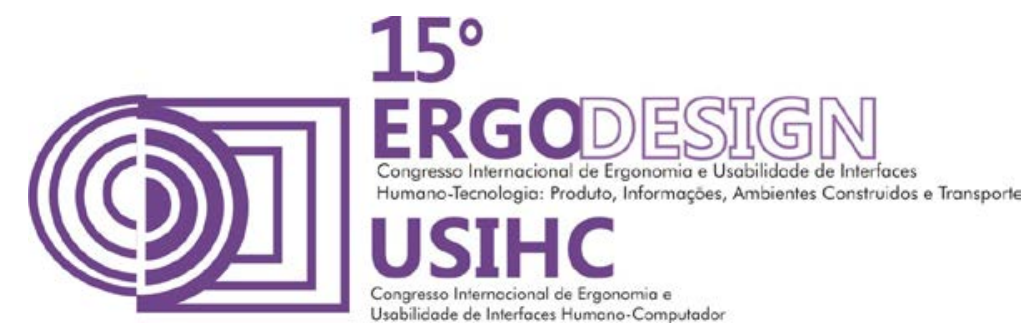

A mandioca divide-se em maniva e raiz, sendo maniva o caule que fica exposto e raiz a parte comestível que se encontra sob o solo (EPAGRI, 2012).

O cultivo da mandioca se dá em etapas definidas, podendo variar de acordo com a região. Estas são:

Preparação do solo: Por meio de aração e gradagem, manual ou mecanizada. Em pequenas propriedades é geralmente manual.

Semeadura: As manivas (parte do caule da mandioca) são cortadas com facão para obtenção dos toletes que devem ter de 15 a $25 \mathrm{~cm}$.

Colheita: É uma das tarefas mais difíceis de mecanizar, em propriedades familiares é feita, na maioria dos casos, manualmente.

Entre as etapas principais de semeadura e colheita, pode ocorrer ainda fertilização e controle de pragas. (OSPINA; CEBALLOS, 2002; ARISTIZÁBAL; SÁNCHEZ, 2007)

\section{COLHEITA DA MANDIOCA}

A colheita da mandioca vária em método e tempo de acordo com a técnica de plantação, esta por sua vez depende do tipo de solo; Em solos argilosos, a plantação das estacas é feita em posição horizontal a $10 \mathrm{~cm}$ de profundidade, em sulcos, facilitando a colheita comercial. Em solos mais pesados/compactados, a plantação das estacas deve ser feita em sulcos, diminuindo assim o esforço físico na colheita. Já em solos de textura arenosa, é recomendado que se coloquem as estacas em posição vertical enterrando-as $5 \mathrm{~cm}$ no solo (OSPINA; CEBALLOS, 2002).

A colheita da mandioca é realizada em etapas, a primeira é o corte e seleção de folhagens e o corte da rama deixando apenas 20 a $40 \mathrm{~cm}$ junto as raízes para possibilitar a extração. A segunda etapa compreende a extração (arranque) das raízes, seguida do recolhimento.

O arranque pode ser manual; no Brasil os solos nos quais são cultivados as raízes dificultam a extração, sendo necessária aplicação de força excessiva e posturas extremas, como pode ser observado na Figura 1.

Em alguns países da América Latina é utilizada a seguinte técnica: amarra-se a rama, com cordas ou correntes, a um cabo que funciona como alavanca para extrair a raiz. Com arrancador, geralmente tem-se uma ferramenta com um cabo, onde próxima de uma das extremidades possui um sistema de engate da rama, funcionando como uma alavanca para retirar a raiz do solo (ARISTIZÁBAL; SÁNCHEZ, 2007). 

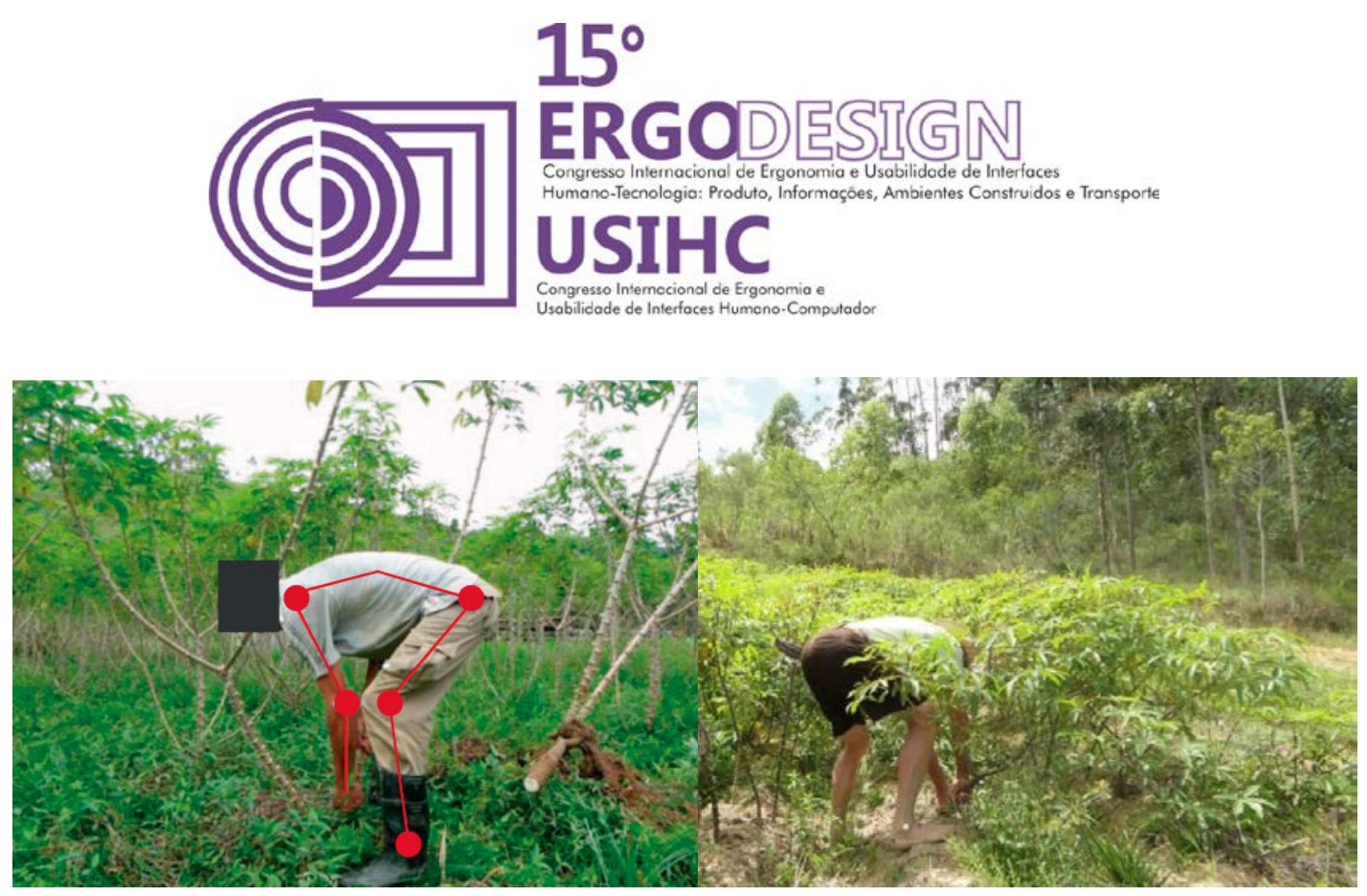

Figura 1: Extração manual de mandioca

\subsection{Extração manual}

Os trabalhadores agrícolas são expostos à atividades com risco musculoesquelético em grande parte de suas atividades, no entanto algumas tarefas se destacam por requerer repetitividade, a colheita evidencia-se por ser necessária em variados cultivos (FATHALLAH, 2010).

Quando da extração manual, prática mais comum nas propriedades agrícolas familiares, o agricultor executa a tarefa apoiando ambos os pés no chão segurando a rama (maniva) com as mãos e a puxando para cima, num movimento que concentra a força nos membros superiores e requer a inclinação do tronco.

Para análise dos riscos musculo-esqueléticos, aos quais os trabalhadores são expostos durante a colheita da mandioca, realizou-se uma simulação com o equipamento de captura de movimento $X$-sens MVN Biomech, para possibilitar a vizualização dos pontos extremos da postura. A simulação foi realizada considerando os percentis 5,50 e 95 e os tipos de terreno, plano ou inclinado.

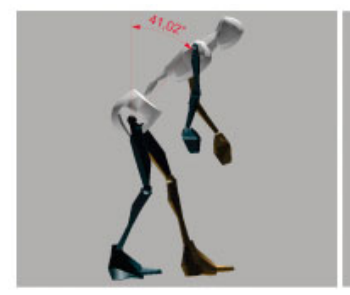

Percentil 5- Terreno plano

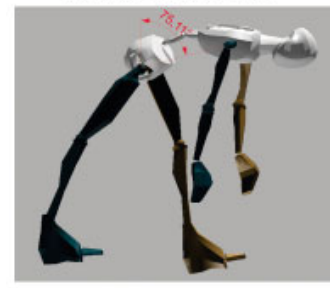

Percentil 95- Terreno inclinado

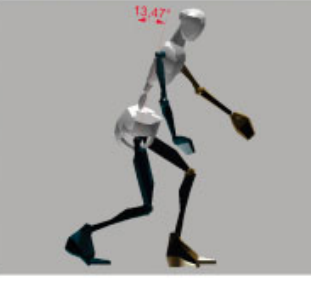

Percentil 5- Terreno inclinado

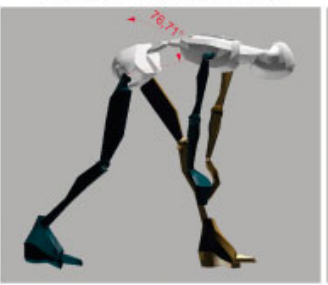

Percentil 95- Terreno plano

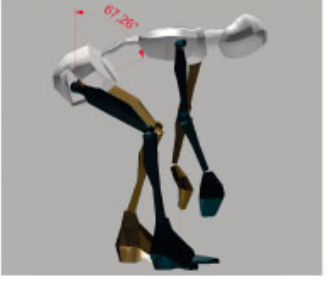

Percentil 50-Terreno plano

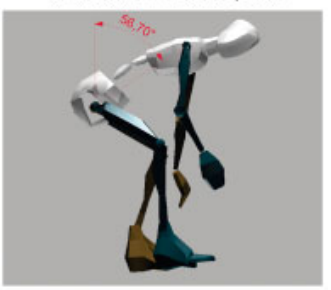

Percentil 50-Terreno inclinado

Figura 2: Modelo biomecânico do software X-Sens 


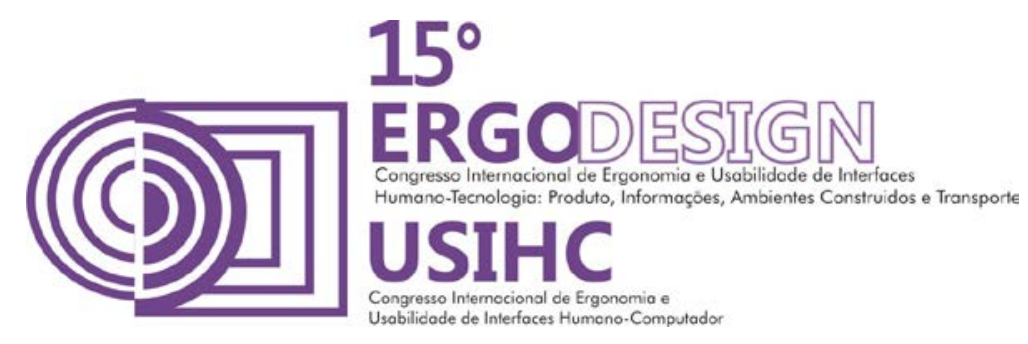

Durante a realização da tarefa, o agricultor adota posturas extremas em diversos pontos, ocorre a flexão e rotação da coluna lombar, que podem causar fraturas e rompimento das fibras anulares. Identifica-se a flexão e a rotação do tronco em ângulos inadequados, segundo lida (2005), a flexão do tronco permite um ângulo de inclinação de $70^{\circ}$, com rotação do tronco de 35․ Durante a extração das raízes o agricultor permanece na postura em pé que, segundo Grandjean e Kroemer (2005) e lida (2005), é altamente fatigante. Além disso, a repetitividade nas ações pode associar-se ao desenvolvimento de tendinites e a síndrome do túnel do carpo na região do punho, (BERNARD, 1997)

Percebe-se que apesar das variações nas angulações posturais dos diversos percentis, os pontos com potencial risco musculo-esquelético coincidem.

Observa-se no gráfico gerado pelo software $X$-sens MVN Studio, os movimentos realizados pelo punho, onde pode-se destacar o maior desvio radial do punho direito, e os movimentos irregulares devido a grande força aplicada para retirar a raiz do solo. Segundo Kapandji (2000), os movimentos do punho se realizam em torno de dois eixos; sendo flexão o movimento de aproximação da superfície palmar da mão, em direção a parte anterior do braço; abdução define-se como o afastamento da mão do eixo do corpo em direção ao polegar (KAPANDJI, 2000). Estes movimentos podem ser verificados em "A" (Figura 5), onde para segurar a rama 0 punho é flexionado e sofre abdução (desvio radial) máxima de $15^{\circ}$.

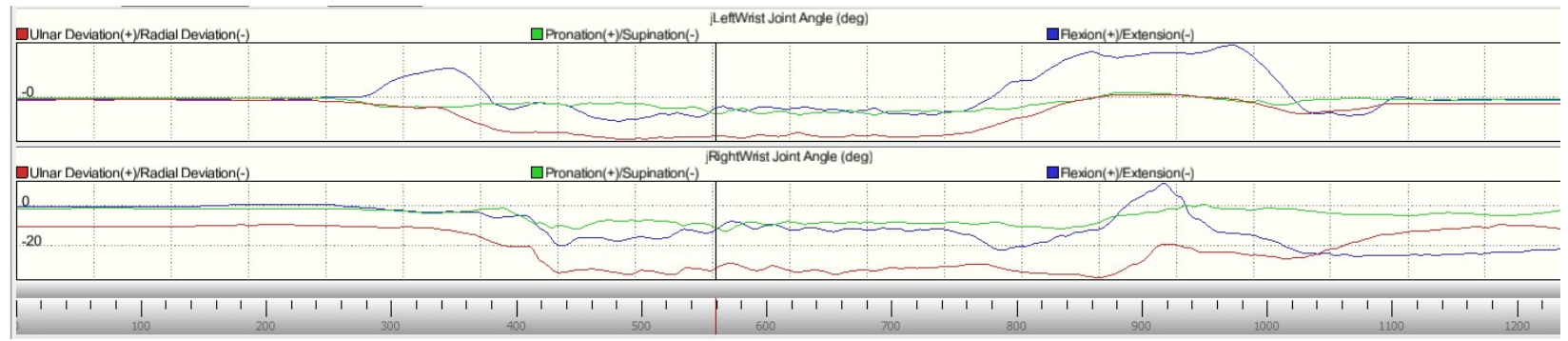

Figura 3: Gráfico dos movimentos dos punhos (gerado pelo software X-sens MVN Studio)

Os ombros também sofrem grandes variações de movimentos, abdução, rotação e flexão. Percebem-se diferentes deslocamentos entre os ombros, assim como a força aplicada é assimétrica em razão da configuração da rama da mandioca.

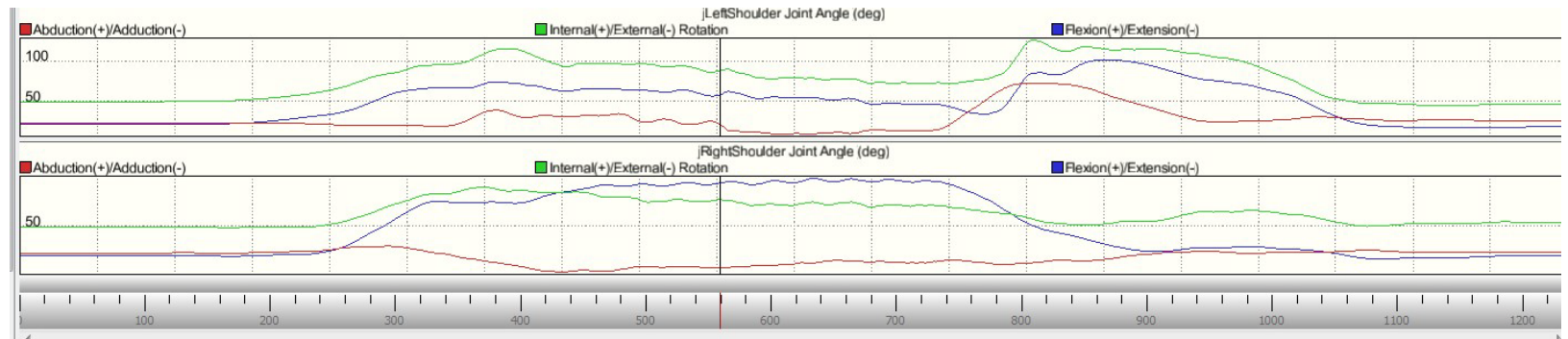

Figura 4: Gráfico dos movimentos dos ombros (gerado pelo software X-sens MVN Studio) 


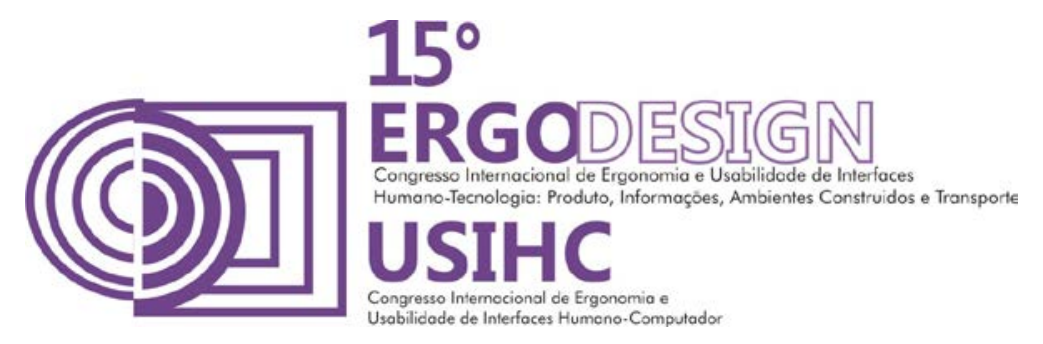

Os movimentos e angulações representados graficamente na Figura 4, podem ser validados observando as imagens em situação real e o modelo biomecânico (Figura 5).
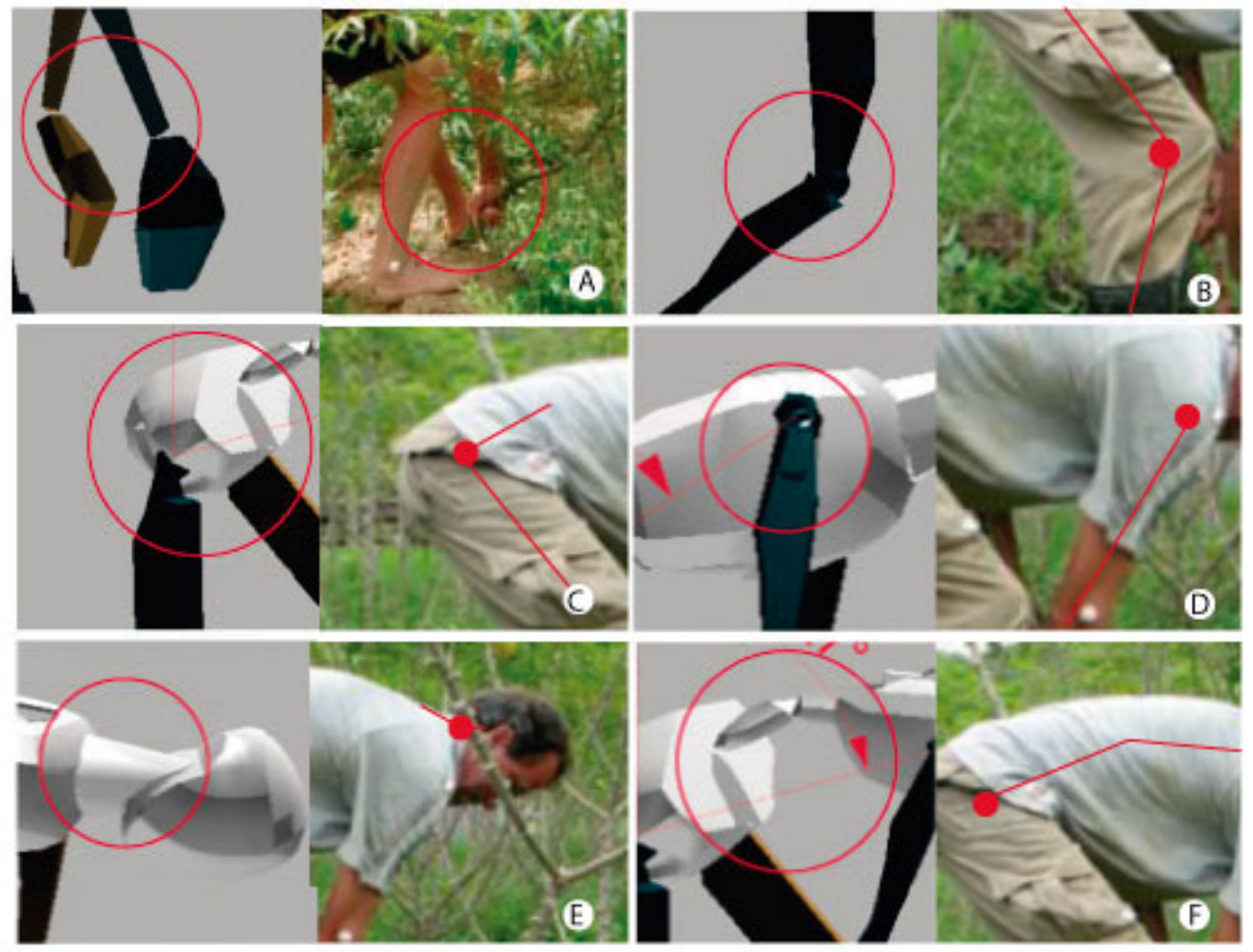

Figura 5: Detalhamento dos pontos posturais da extração manual de mandioca

Observa-se que a posição do punho ilustrada em " $A$ " é claramente inadequada, o risco é acentuado pela repetitividade da tarefa e a força aplicada. Kapandji (2000), elucida que o complexo articular do punho possui dois graus de liberdade, a rotação simultânea em torno dos dois eixos resulta na circundução, a rotação do punho observada em "A". Movimentos intensos do punho repetitivos, combinados ou não com outros fatores de risco, contribuem para 0 desenvolvimento de lesões músculoesqueléticas relacionadas ao trabalho (BARR; BARBE; CLARK, 2004).

Ainda que a postura em pé seja altamente fatigante, a leve flexão dos joelhos observada em "B" diminui a carga sobre os discos da região lombar devido à curvatura da coluna (KROEMER; GRANDJEAN, 2005). No entanto, quando a flexão atinge angulação menor que $90^{\circ}$ a força concentrada sobre o joelho pode causar distúrbios na região (IIDA, 2005).

A flexão do tronco observada em "C" é considerada inadequada por diversos autores (WADDELL; BURTON, 2000; IIDA, 2005; KROEMER; GRANDJEAN, 2005), quando combinada com o manuseio de cargas o risco de lesão é ainda maior. Ainda segundo Kroemer e Grandjean (2005), a lesão da coluna é cumulativa, a dor não é sentida subitamente, torna-se intensa com lesões constantes, como é o caso dos danos ocupacionais. 


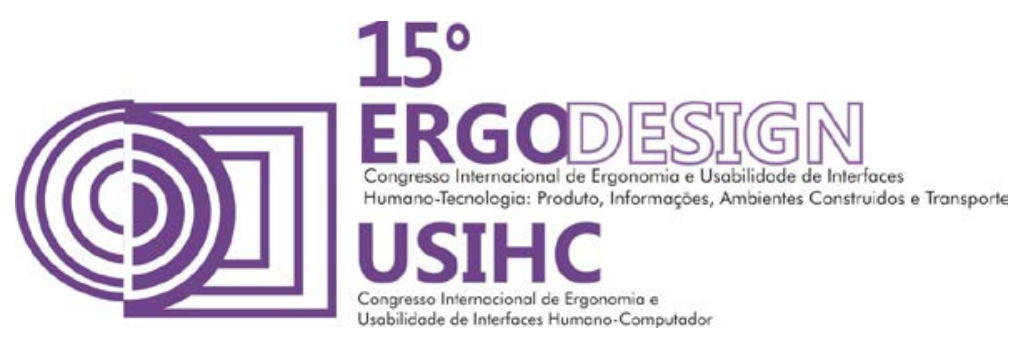

A dor nos ombros está entra as queixas mais frequentes entre trabalhadores, sendo que grande parte das atividades envolve o esforço dos músculos da região, observada em "D" (WESTGAARD; WINKEL, 1996). A força aplicada nos membros superiores durante a extração da mandioca, agrava os fatores de risco expostos. Segundo Kapandji (2000), o ombro é a articulação com maior mobilidade do corpo humano. Durante a tarefa o ombro realiza 0 movimento de flexão com leve adução para alcançar a rama da mandioca. Inevitavelmente, combinado com os outros fatores citados o pescoço também sofre posturas inadequadas, conforme ilustrado em "E". Segundo Westgaard e Winkel (1992), as queixas de dores nos ombros e pescoço estão geralmente associadas. Com a inclinação do tronco, a cabeça fica sem apoio, o que gera uma postura altamente fatigante para os músculos da região do pescoço que têm de suportar a carga (IIDA, 2005)

A carga aplicada sobre a coluna lombar é a principal causa de lesões ocupacionais, influencia a qualidade de vida dos trabalhadores, além de envolver questões econômicas e sociais (MARRAS, 2000). Durante a extração manual da mandioca a postura adotada afeta extremamente a região lombar, sendo a principal queixa dos trabalhadores e motivo para afastamento temporário da atividade. Segundo Kroemer e Grandjean (2005), a carga na coluna vertebral é naturalmente maior nas cinco vértebras lombares. Com a postura adotada, observada em "F", a pressão nos discos da coluna lombar é ainda mais acentuada devido ao efeito alavanca. Em virtude da força aplicada para retirar a rama do solo, há um considerável aumento da pressão nas cavidades abdominais, devido à contração dos músculos. A pressão intra-abdominal é proporcional à carga aplicada na coluna lombar (KROEMER; GRANDJEAN, 2005).

O trabalho pode causar distúrbios músculoesquléticos, agravá-los e até mesmo impedir a reabilitação. Por outro lado, intervenções ergonômicas podem evitar os distúrbios e auxiliar na recuperação dos trabalhadores (HALPERN, 1992). Experiências bem sucedidas, comprovam que a ergonomia aplicada à postos de trabalho de diversos setores obtiveram resultados satisfatórios quanto à prevenção de lesões na coluna (LOISEL et al, 2000; HESS et al, 2004; CHOOBINEH et al, 2010)

Tratando-se da extração de raiz de mandioca, destaca-se o potencial de aplicação da ergonomia para beneficiar os trabalhadores, prevenindo danos à saúde e aumentando a produtividade do setor. Uma ferramenta ergonômica que auxiliasse na extração da rama, poderia reduzir os riscos músculoesqueléticos da tarefa. Salientando que a ferramenta manual citada refere-se a instrumento que não necessita de instalação, mecanização ou fonte de energia, justificada pela obrigatoriedade de que a ferramenta possua baixo custo, devido as limitações dos agricultores familiares. Assim, a partir dos pontos observados, pontuam-se as diretrizes para uma ferramenta manual que poderia reduzir os impactos da atividade à saúde do usuário.

- Evitar a torção do punho com pega adequada que o mantenha em posição mais próxima da natural;

- Impedir ou diminuir a flexão do tronco, consequentemente evitando carga extrema sobre a coluna lombar;

- Diminuir a flexão do ombro e evitar a adução, mantendo o pescoço em angulação máxima de $15^{\circ}$ 


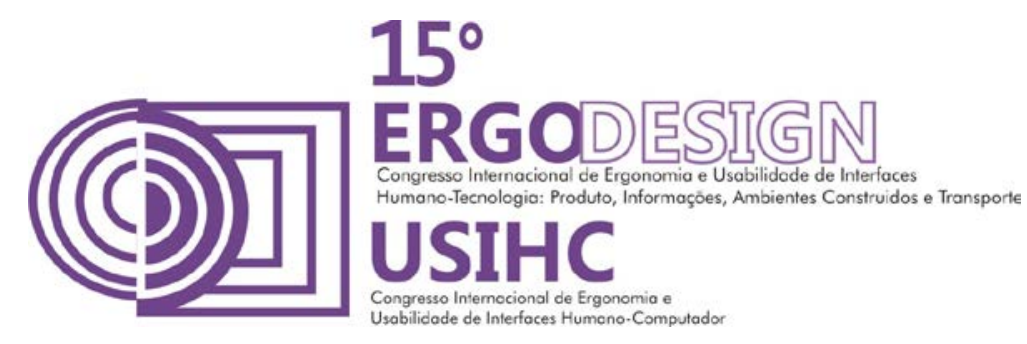

- Reduzir a força necessária para extrair a raiz do solo.

\section{CONCLUSÕES}

A análise postural da extração manual de mandioca, evidenciou a gravidade dos riscos aos que são expostos os trabalhadores e a necessidade de aprofundar pesquisas voltadas para a agricultura familiar. Percebe-se a importância do setor para a economia nacional e mundial e o potencial evidente de melhoria por meio da ergonomia, que devidamente aplicada pode auxiliar no desenvolvimento ou melhoria de ferramentas e soluções que venham a prevenir danos à saúde do agricultor. Evidencia-se também a importância de utilização de tecnologias como o rastreamento de movimentos $3 \mathrm{D}$, utilizado nesta pesquisa, que permitem identificar com maior clareza os fatores de risco, além de gerar dados mais precisos para análise.

A oportunidade de desenvolver pesquisas aplicadas nesta área, evidencia-se pela escassez das mesmas. As diretrizes propostas podem nortear o futuro desenvolvimento de ferramentas que viriam a facilitar a extração de mandioca, diminuindo os riscos à saúde do trabalhador e aumentando a produtividade. Além disso, destaca-se a importância de que as soluções propostas sejam de baixo custo, sendo uma das principais características da agricultura familiar a carência de recursos. Como desdobramentos da pesquisa poderia-se pontuar, continuidade de pesquisas na área e aplicação prática dos conhecimentos em ferramentas ergonômicas. Definindo-se então as próximas etapas:

- Desenvolver protótipos das ferramentas para teste em situações reais;

- Análisar os aspectos biomecânicos da tarefa com a utilização da ferramenta;

- Avaliação da variação de produtividade no arranque manual e com utilização de ferramenta.

\section{REFERÊNCIAS BIBLIOGRÁFICAS}

AGSAFE. Occupational Injuries in California Agriculture: 1981-1990. AgSafe, University of California Division of Agricultural and Natural Resources, Oakland, CA.

ARISTIZÁBAL, Johanna; SÁNCHEZ, Teresa. Guía técnica para producción y análisis de almidón de yuca. Roma: Organización de Las Naciones Unidas Para La Agricultura y La Alimentación, 2007.

BARR, A. E.; BARBE, M. F.; CLARK, B. D. Work-Related Musculoskeletal Disorders of the hand and wrist: epidemiology, pathophysiology, and sensorimotor changes. Journal of Orthopedic and Sports Physical Therapy, v. 34, n. 10, p. 610-627, 2004.

BERNARD, B. P. Musculoskeletal disorders and workplace factors: a critical review of epidemiologic evidence for work-related musculoskeletal disorders of the neck, upper extremity, and low back. Cincinnati: NIOSH, 1997.

$\mathrm{CHOOBINEH}$, Alireza. et al. The impact of ergonomics intervention on psychosocial factors and musculoskeletal symptoms among office workers. International Journal Of Industrial Ergonomics, $n$. 41, p.671-676, set. 2011. 


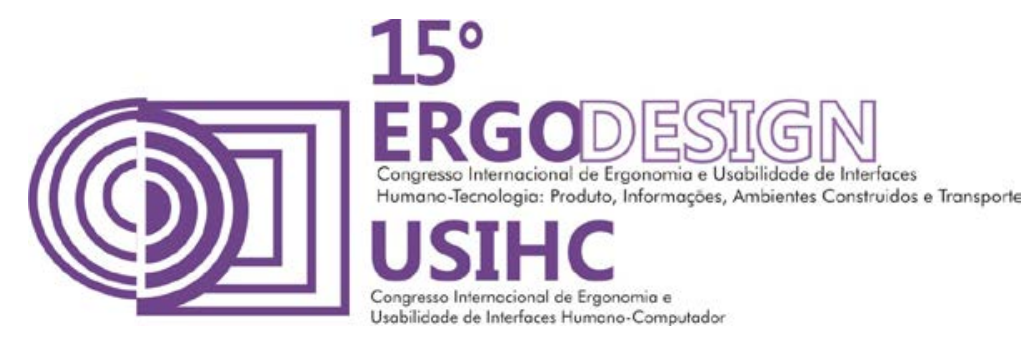

DINIZ, Clarissa Fernandes; SCHARMACH, Andreia Luciana Rosa. Estudo sobre a percepção do impacto do sistema cooperativo de agricultura familiar nos municípios de Mafra, Papanduva e Monte Castelo. Ágora: R. Divulg. Cient, v. 18, n. 1, p.5-16, 2011.

Dziedzoave, N.T., Abass, A.B., Amoa-Awua, W.K.A., Sablah, M. Quality management manual for production of high quality cassava flour. International Institute of Tropical Agriculture.

EMBRAPA. Mandioca. Disponível em: <https://www.embrapa.br/mandioca-efruticultura/cultivos/mandioca>. Acesso em: 07 jun. 2014.

EPAGRI - Órgão oficial de Extensão Rural e Pesquisa Agropecuária do estado de Santa Catarina. 2012. Disponível em: <http://www.epagri.sc.gov.br>. Acesso em: 23 mai. 2014.

FAO. Production data. Disponível em: <http://faostat3.fao.org/browse/Q/QC/E>. Acesso em: 07 nov. 14.

FATHALLAH, Fadi A.. Musculoskeletal disorders in labor-intensive agriculture. Applied Ergonomics, n. 41, p.738-743, fev. 2010.

FLEMING, Ivo. Diagnóstico Ergonômico Preliminar em Comunidade Agrícola com Produção Diversificada. 2003. 139 f. Dissertação (Mestrado) - Curso de Departamento de Engenharia de Produção e Sistemas, UFSC, Florianopolis, 2003.

FRANÇA, Caio Galvão de. GROSSI, Mauro Eduardo Del. MARQUES, Vicente P. M. de Azevedo. O censo agropecuário 2006 e a agricultura familiar no Brasil. Brasília: MDA, 2009.

GIL, Antonio Carlos. Como elaborar projetos de pesquisa. 4. ed. São Paulo: Atlas, 2002.

GUÉRIN, F. et al. Compreender o trabalho para transformá-lo: a prática da ergonomia. São Paulo, Edgard Blucher, 2001.

HALPERN, M.. Prevention of low back pain: basic ergonomics in the workplace and the clinic. Bailliere's Clinical Rheumatology, v. 6, n. 3, p.705-730, out. 1992.

HESS, Jennifer A. et al. A participatory ergonomics intervention to reduce risk factors for low-back disorders in concrete laborers. Applied Ergonomics, n. 35, p.427-441, 2004.

HILLOCKS, R. J; THRESH, J. M; BELLOTTI, A. C. Cassava Biology, Production and Utilization. Cabi Publishing, 2001.

IBGE- Instituto Brasileiro de Geografia e Estatística - Censo Agropecuário 2006. Rio de Janeiro: 2006.

IEA- International Ergonomics Association. Definição Internacional de Ergonomia. San Diego, USA: 2000

IIDA, Itiro. Ergonomia: Projeto e produção. 2. ed. São Paulo: Blucher, 2005.

JAFRY, Tahseen; O'NEILL, David H. The application of ergonomics in rural development: a review. Applied Ergonomics, n. 31, p.263-268, 2000.

KAPANDJI, A. I. Fisiologia articular: Esquemas comentados de mecânica humana. 5. ed. Rio de Janeiro: Panamericana, 2000.

KROEMER, K. H. E; GRANDJEAN, E. (Etienne). Manual de ergonomia : adaptando o trabalho ao homem. 5. ed. Porto Alegre: Bookman, 2005.

LOISEL, Patrick et al. Implementation of a participatory ergonomics program in the rehabilitation of workers suffering from subacute back pain. Applied Ergonomics, n. 32, p.53-60, 2001.

MARCONI, Marina de Andrade; LAKATOS, Eva Maria. Fundamentos de metodologia científica. 5. ed. São Paulo : Atlas 2003. 


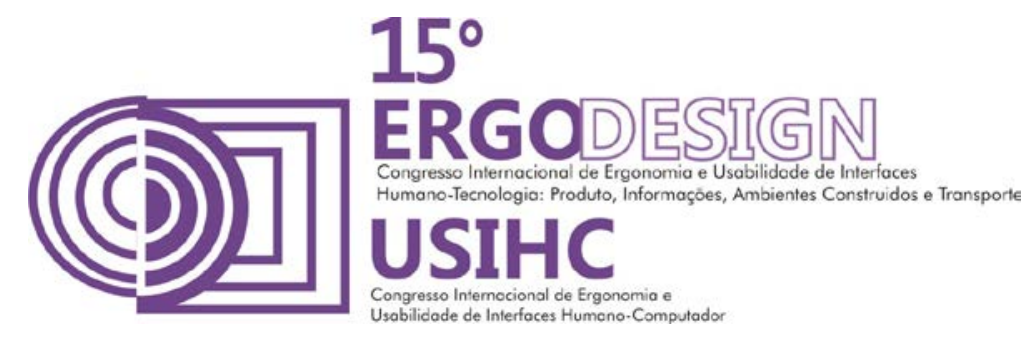

MARRAS, W. Occupational low back disorders causation and control. Ergonomics, Londres, vol. 43, n. 7, p. 880-902, jul. 2000.

MDA- Ministério do Desenvolvimento Agrário. Plano Safra da Agricultura Familiar: 2014/2015. 2014.

MDS- Ministério do Desenvolvimento Social e Combate à Fome, 2009. Disponível em: <http://www.mds.gov.br> Acesso em 28 fev. 2014.

Ministério da Previdência Social, Empresa de Tecnologia e Informações da Previdência Social. Anuário Estatístico da Previdência Social. 21ª edição, 2012.

OSPINA, Bernardo; CEBALLOS, Hernán. La Yuca en el tercer milenio: sistemas modernos de producción, procesamiento, utilización y comercialización. Cali, Colombia: Centro Internacional de Agricultura Tropical, 2002.

RURAL FORUM. The Family Farming World Conference. Disponível em: <http://www.ruralforum.net/ffwconference/default.asp?id=en>. Acesso em: 09 dez. 2013.

SILVA, Edna Lúcia da; MENEZES, Estera Muszkat. Metodologia da pesquisa e elaboração de dissertação - 4. ed. rev. atual. - Florianópolis: UFSC, 2005.

United States Department Of Labor. OSHA Technical Manual (OTM) Section VII: Chapter 1. 1999. Disponível em: <https://www.osha.gov/dts/osta/otm/otm_vii/otm_vii_1.html\#3>. Acesso em: 03 maio 2014.

WADDELL, G.; BURTON, A. K. Occupational health guidelines for the management of low back pain at work: evidence review. Occupational Medicine, Oxford, vol. 51, n. 2, p. 124-135, fev. 2001.

WINKEL, Jorgen; WESTGAARD, Rolf. Occupational and individual risk factors for shoulder-neck complaints: Part II - The scientific basis (literature review) for the guide. International Journal Of Industrial Ergonomics, n. 10, p.85-104, 1992.

\section{AGRADECIMENTOS}

A Fundação de Amparo à Pesquisa e Inovação do Estado de Santa Catarina (FAPESC), a Coordenação de Aperfeiçoamento de Pessoal de Nível Superior (CAPES), ao Conselho Nacional de Desenvolvimento Científico e Tecnológico (CNPq), ao Órgão oficial de Extensão Rural e Pesquisa Agropecuária do estado de Santa Catarina (EPAGRI) e ao Núcleo de Gestão de Design da Universidade Federal de Santa Catarina (NGD/UFSC), que viabilizaram a pesquisa presente neste trabalho. 